\title{
Survei Tingkat Kondisi Fisik Vo2Max Atlet Pada Klub Futsal Putri di Kota Bengkulu
}

\section{Survey of The Physical Condition Level od Vo2Max Atheletes in Women's Futsal Clubs in Bengkulu City}

\author{
Dera Selvi Ulandari' ${ }^{1}$, Dian Pujianto², Andika Prabowo ${ }^{3}$, Defliyanto ${ }^{4}$. \\ ${ }^{1234}$ Pendidikan Jasmani, Universitas Bengkulu, Jl. WR. Supratman Kandang Limun, Bengkulu, \\ 3871A, Indonesia
}

\begin{abstract}
Abstrak
Penelitian ini bertujuan untuk mengetahui kondisi fisik $\mathrm{VO}_{2} \mathrm{Max}$ atlet pada klub futsal putri di Kota Bengkulu. Jenis penelitian ini adalah penelitian deskriptif dengan pendekatan kualitatif. Subjek penelitian ini adalah seluruh klub futsal putri di kota Bengkulu yang berjumlah 60 orang atlet dari 7 klub. Teknik pengumpulan data dalam penelitian ini menggunakan metode tes dan pengukuran $\mathrm{VO}_{2} \mathrm{Max}$ dan dokumentasi. Instrument yang digunakan dalam penelitian ini adalah menggunakan tes $M F T$ (Multistage Fitness Test). Teknik analisis data menggunakan analisis deskriptif seperti halnya nilai rata-rata, nilai tertinggi, nilai terendah dan persentase. Berdasarkan data yang diperoleh hasil penelitian survei kondisi fisik $\mathrm{VO}_{2} \mathrm{Max}$ atlet pada klub futsal putri di kota Bengkulu berada pada rata-rata nilai sebesar 30.61, dengan hasil tersebut berdasarkan norma standarisasi dinyatakan dalam kategori kurang.
\end{abstract}

Kata kunci: Atlet Putri, Futsal, Kondisi Fisik, Vo2Max

\begin{abstract}
The research mode to find out physical condition $\mathrm{VO}_{2} \mathrm{Max}$, of athletes at women's futsal club in Bengkulu city. The type of the research is qualitative descriptive. Subjects in the research is all of women futsal club in Bengkulu wich 60 athlets from 7 club. The collection technique of data is study test, measurements $\mathrm{VO}_{2} \mathrm{Max}$ and documentation. The instruments used in the research is MFT test (Multistage Fitness Test). Analysis technique is descriptive such as average velue, the highest score, the lowest score, and percentage. Based on the data obtained the results of the research on physical condition $\mathrm{VO}_{2}$ Max athletes in women futsal club of Bengkulu city with the velue 30.61, based on standarai cation norms included in the low category.
\end{abstract}

Keywords: Futsal, Physical Condition, Vo2Max, Women Futsal 



\section{PENDAHULUAN}

Masyarakat Indonesia semakin menyadari akan pentingnya menjaga kesehatan, baik sehat secara jasmani atau rohani. Sekarang masyarakat Indonesia mulai banyak meminati olahraga untuk mengisi waktu luang baik bersama keluarga maupun bersama teman-teman, seperti bermain futsal, bulutangkis, bola voli, jogging. Berdasarkan (UU RI, 2005) "Olahraga adalah segala kegiatan yang sistematis untuk mendorong, membina, serta mengembangkan potensi jasmani, rohani, dan sosial". Olahraga adalah bagian dari aktivitas manusia dalam kehidupan sehari-hari yang berguna untuk membentuk kesehatan jasmani dan rohani yang sehat. Sampai sekarang olahraga memberikan kontribusi yang positif dan nyata bagi peningkatan kesehatan masyarakat (Arifianto et al., 2021)

Futsal merupakan salah satu cabang olahraga yang termasuk dalam permainan bola besar (Raibowo, Ilahi, et al., 2021) dan merupakan permainan yang sangat cepat dan dinamis, dari segi lapangan yang relatif kecil, hampir tidak ada ruangan untuk membuat kesalahan (Lhaksana, 2011). Tim futsal putri di Bengkulu mulai aktif kembali yaitu pada tahun 2017, pada saat itu masih sedikit klub futsal putri yang benar-benar aktif melakukan latihan dengan rutin, diselenggarakannya turnamen-turnamen seperti turnamen HMTI di Universitas Dehasen, HMTI di Universitas UMB yang dilaksanakan setiap tahun hal ini menjadi penyemangat untuk atlet-atlet futsal putri di kota Bengkulu.

Pada Tahun 2020 sampai sekarang di kota Bengkulu sudah memiliki tujuh klub yaitu Bengkulu Futsal Club, Patrimony United, Jugador Bonita Raflesia, MU4 FC, Bengkulu Raya Angel, Bunga Kenanga, dan Futsal UKM FORKIP UNIB yang aktif dalam melaksanakan latihan. Klub futsal putri di kota Bengkulu saat ini memang sudah berkembang dengan baik namun masih ada beberapa kendala yang dialami oleh klub-klub futsal putri di kota Bengkulu, yaitu masih ada beberapa atlet yang memiliki kondisi fisik VO2Max yang masih kurang. Kurangnya tingkat kondisi fisik VO2Max pada atlet klub futsal putri di Bengkulu memiliki beberapa faktor yang mempengaruhinya, seperti waktu latihan di klubklub futsal putri di kota Bengkulu yang kurang efisien, dan atlet futsal putri di kota Bengkulu masih sangat kurang untuk kesadarannya untuk menambah latihan sendiri atau hanya sekedar menjaga kondisi fisik agar tetap prima, biasanya atlet 
di klub futsal putri di kota Bengkulu hanya menjalankan latihan saat jadwal latihan di laksanakan di klubnya masing-masing sehingga tidak ada kesadaran diri sendiri untuk menambah latihan di luar jam latihan. Faktor lainnya juga yaitu datang dari pelatihnya, masih ada beberapa klub yang pelatihnya belum menerapkan program latihan yang benar-benar memfokuskan untuk menunjang kondisi fisik VO2Max atletnya.

Seperti yang diamati oleh peneliti setiap mengikuti pertandingan ada beberapa klub yang atletnya mengalami kondisi fisik yang kurang, hal ini mengakibatkan saat pertandingan pemain sudah kehilangan konsentrasi, yang menyebabkan atlet mengalami kelelahan. Seperti yang diketahui bahwa konsentrasi merupakan aspek yang sangat penting dalam olahraga prestasi (Nopiyanto et al., 2021; Raibowo, Jatra, et al., 2021). Beberapa kali tim futsal putri mengikuti turnamen di luar daerah Bengkulu seperti Lubuklinggau, Palembang, Jambi dan di turnamen-turnamen itu tim Bengkulu selalu mengalami kekalahan di semifinal dengan klub dari luar Bengkulu, banyak faktor yang menyebabkan salah satunya kondisi fisik yang berkurang, tim Bengkulu selalu kebobolan di menit- menit akhir dengan selisih gol yang sedikit. Berdasarkan latar belakang masalah di atas saya tertarik untuk melaksanakan penelitian dengan judul "Survei Tingkat Kondisi Fisik Vo2max Atlet Pada Klub Futsal Putri di Kota Bengkulu"

\section{METODE}

Berdasarkan permasalahan dan tujuan penelitian yang telah dibahasa sebelumnya, maka metode yang digunakan dalam penelitian ini yaitu metode deskriptif pendekatan kualitatif. Penelitian deskriptif yaitu metode yang digunakan peneliti untuk melakukan penelitian suatu objek, suatu sistem pemikiran, peristiwa yang dialami sekarang atau status kelompok manusia (Sugiyono, 2018). Penelitian deskriptif ini bertujuan untuk menggambarkan secara sistematis dan akurat mengenai fakta-fakta, hubungan atau sifat-sifat antara Fenomena yang diselidiki. Tempat dan waktu penelitian ini dilaksanakan di klubklub futsal putri di kota Bengkulu. Subjek yang digunakan dalam penelitian ini adalah 60 atlet yang aktif di klub futsal putri yang ada di kota Bengkulu yang berjumlah 7 klub 
Tabel 1. Subjek Penelitian

\begin{tabular}{ccc}
\hline No & Nama Klub & Jumlah Atlet \\
\hline $\mathbf{1}$ & Bengkulu Futsal Club & 10 \\
$\mathbf{2}$ & Patrimony United & 10 \\
$\mathbf{3}$ & Jugador Bonita Raflesia & 9 \\
$\mathbf{4}$ & Mu4 Fc & 8 \\
$\mathbf{5}$ & Bengkulu Raya Angels & 8 \\
$\mathbf{6}$ & Bunga Kenanga & 7 \\
$\mathbf{7}$ & Futsal UKM FORKIP UNIB & 8 \\
& Jumlah & 60 \\
\hline
\end{tabular}

Teknik pengumpulan data dalam penelitian ini menggunakan metode tes dan pengukuran VO2Max dan dokumentasi, sedangkan instrumen yang digunakan dalam penelitian ini adalah menggunakan tes MFT (Multistage Fitness Test) dan Dokumentasi. Teknik analisis data ini dilakukan dengan menganalisi data yang telah diperoleh dengan menggunakan deskriptif, seperti halnya nilai rata-rata, nilai tertinggi, nilai terendah dan dimasukan dalam tebel distribusi frekuensi berdasarkan persentase, dengan rumus persentase digunakan adalah $\mathrm{P}=$ $\mathrm{f} / \mathrm{n} \times 100 \%$ (Arikunto, 2010) Setelah data diperoleh peneliti dapat membuat kesimpulan serta saran sehingga dapat diperoleh hasil akhir penelitian dengan menggunakan norma standarisasi untuk daya tahan aerobik. Norma standarisasi daya tahan aerobik (VO2Max).

Tabel 2. Norma Klasifikasi Tingkat Vo2Max Putri (Mi/Kg/Min)

\begin{tabular}{ccc}
\hline No & Vo2Max & Kategori \\
\hline $\mathbf{1}$ & $>49$ & Baik Sekali \\
$\mathbf{2}$ & $39-48,9$ & Baik \\
$\mathbf{3}$ & $31-38,9$ & Cukup \\
$\mathbf{4}$ & $24-30,9$ & Kurang \\
$\mathbf{5}$ & $<23,9$ & Sangat Kurang \\
\hline
\end{tabular}

\section{HASIL}

Secara keseluruhan hasil penelitian yang diperoleh dari klub futsal putri Bengkulu futsal club yang berjumlah 10 atlet menunjukan tingkat kondisi fisik VO2Max atlet yaitu nilai minimum VO2Max sebesar $=26.0$, nilai maksimal VO2Max sebesar $=39.2$, dan nilai rata-rata sebesar $=32.36$ 
Tabel 3. Persentase Tingkat Kondisi Fisik $\mathrm{VO}_{2} \mathrm{Max}$ Klub Futsal BengkuluFutsal Club Kota Bengkulu

\begin{tabular}{rcccc}
\hline NO & $\boldsymbol{V O}_{2} \boldsymbol{M A} \boldsymbol{X}$ & Kategori & Frekuensi & Persentase \\
\hline 1. & $\geq 49$ & Baik Sekali & 0 & $0 \%$ \\
2. & $39-48,9$ & Baik & 1 & $10 \%$ \\
3. & $31-38,9$ & Cukup & 7 & $70 \%$ \\
4. & $24-30,9$ & Kurang & 2 & $20 \%$ \\
$\mathbf{5 .}$ & $<23,9$ & Sangat Kurang & 0 & $0 \%$ \\
& & & $\mathbf{1 0}$ & $\mathbf{1 0 0 \%}$
\end{tabular}

Berdasarkan Tabel 3, dapat disimpulkan bahwa atlet yang memiliki kondisi VO2Max dengan kategori baik sekali berjumlah $0(0 \%)$, baik 1 atlet (10\%), cukup 7 atlet (70\%), kurang 2 atlet (20\%), sedangkan kategori sangat kurang $0(0 \%)$.

Secara keseluruhan hasil penelitian yang diperoleh dari klub futsal putri Patrimony United yang berjumlah 10 atlet menunjukan tingkat kondisi fisik VO2Max atlet yaitu nilai minimum VO2Max sebesar $=26.8$, nilai maksimal VO2Max sebesar $=37.5$, dan nilai rata-rata sebesar $=32.05$.

Tabel 4. Persentase Tingkat Kondisi Fisik $\mathrm{VO}_{2} \mathrm{Max}$ Klub Futsal Patrimony United Kota Bengkulu

\begin{tabular}{rcccc}
\hline NO & $\boldsymbol{V O} \boldsymbol{O}_{\mathbf{2}} \boldsymbol{M} \boldsymbol{A} \boldsymbol{X}$ & Kategori & Frekuensi & Persentase \\
\hline $\mathbf{1 .}$ & $\geq 49$ & Baik Sekali & 0 & $0 \%$ \\
$\mathbf{2 .}$ & $39-48,9$ & Baik & 1 & $10 \%$ \\
$\mathbf{3 .}$ & $31-38,9$ & Cukup & 7 & $70 \%$ \\
$\mathbf{4 .}$ & $24-30,9$ & Kurang & 3 & $30 \%$ \\
$\mathbf{5 .}$ & $<23,9$ & Sangat Kurang & 0 & $0 \%$ \\
& & & $\mathbf{1 0}$ & $\mathbf{1 0 0 \%}$ \\
& Jumlah & &
\end{tabular}

Berdasarkan Tabel 4, dapat disimpulkan bahwa atlet yang memiliki kondisi VO2Max dengan kategori baik sekali berjumlah $0(0 \%)$, baik $0(0 \%)$, cukup 7 atlet (70\%), kurang 3 atlet (30\%), sedangkan kategori sangat kurang 0 $(0 \%)$. Secara keseluruhan hasil penelitian yang diperoleh dari klub futsal putri Jugador Bonita Raflesia yang berjumlah 9 atlet menunjukan tingkat kondisi fisik VO2Max atlet yaitu nilai minimum VO2Max sebesar $=26.0$, nilai maksimal VO2Max sebesar $=36.4$, dan nilai rata-rata sebesar $=31.64$. 
Tabel 5. Persentase Tingkat Kondisi Fisik $\mathrm{VO}_{2} \mathrm{Max}$ Klub Futsal Jugador Bonita

\begin{tabular}{|c|c|c|c|c|}
\hline NO & $V O_{2} M A X$ & Kategori & Frekuensi & Persentase \\
\hline 1. & $\geq 49$ & Baik Sekali & 0 & $0 \%$ \\
\hline 2. & $39-48,9$ & Baik & 0 & $0 \%$ \\
\hline 3. & $31-38,9$ & Cukup & 6 & $66,6 \%$ \\
\hline 4. & $24-30,9$ & Kurang & 3 & $33,3 \%$ \\
\hline 5. & $<23,9$ & Sangat Kurang & 0 & $0 \%$ \\
\hline \multicolumn{3}{|c|}{ Jumlah } & 10 & $100 \%$ \\
\hline
\end{tabular}

Berdasarkan Tabel 5, dapat disimpulkan bahwa atlet yang memiliki kondisi VO2Max dengan kategori baik sekali berjumlah $0(0 \%)$, baik $0(0 \%)$, cukup 6 atlet (66.6\%), kurang 3 atlet (33.3\%), sedangkan kategori sangat kurang 0 $(0 \%)$. Secara keseluruhan hasil penelitian yang diperoleh dari klub futsal putri Jugador Bonita Raflesia yang berjumlah 8 atlet menunjukan tingkat kondisi fisik VO2Max atlet yaitu nilai minimum VO2Max sebesar $=24.4$, nilai maksimal VO2Max sebesar $=32.9$, dan nilai rata-rata sebesar $=28.45$.

Tabel 6. Persentase Tingkat Kondisi Fisik $\mathrm{VO}_{2} \mathrm{Max}$ Klub Futsal Mu4 Fc Kota

\begin{tabular}{ccccc}
\multicolumn{5}{c}{ Bengkulu } \\
\hline NO & $\boldsymbol{V O}_{2} \boldsymbol{M} \boldsymbol{A} \boldsymbol{X}$ & Kategori & Frekuensi & Persentase \\
\hline $\mathbf{1 .}$ & $\geq 49$ & Baik Sekali & 0 & $0 \%$ \\
$\mathbf{2 .}$ & $39-48,9$ & Baik & 0 & $0 \%$ \\
$\mathbf{3 .}$ & $31-38,9$ & Cukup & 3 & $37,5 \%$ \\
$\mathbf{4 .}$ & $24-30,9$ & Kurang & 3 & $62,5 \%$ \\
$\mathbf{5 .}$ & $<23,9$ & Sangat Kurang & 0 & $0 \%$ \\
& & & $\mathbf{1 0}$ & $\mathbf{1 0 0} \%$ \\
\hline
\end{tabular}

Berdasarkan Tabel 6, dapat disimpulkan bahwa atlet yang memiliki kondisi VO2Max dengan kategori baik sekali berjumlah $0(0 \%)$, baik $0(0 \%)$, cukup 3 atlet (37.5\%), kurang 5 atlet (62.5\%), sedangkan kategori sangat kurang 0 $(0 \%)$. Secara keseluruhan hasil penelitian yang diperoleh dari klub futsal putri Bengkulu Raya Angels yang berjumlah 8 atlet menunjukan tingkat kondisi fisik VO2Max atlet yaitu nilai minimum VO2Max sebesar $=25.6$, nilai maksimal VO2Max sebesar $=32.6$, dan nilai rata-rata sebesar $=30.27$. 
Tabel 7. Persentase Tingkat Kondisi Fisik $\mathrm{VO}_{2} \mathrm{Max}$ Klub Futsal Bengkulu Raya

\begin{tabular}{|c|c|c|c|c|}
\hline NO & $V O_{2} M A X$ & Kategori & Frekuensi & Persentase \\
\hline 1. & $\geq 49$ & Baik Sekali & 0 & $0 \%$ \\
\hline 2. & $39-48,9$ & Baik & 0 & $0 \%$ \\
\hline 3. & $31-38,9$ & Cukup & 5 & $62,5 \%$ \\
\hline 4. & $24-30,9$ & Kurang & 3 & $37,5 \%$ \\
\hline 5. & $<23,9$ & Sangat Kurang & 0 & $0 \%$ \\
\hline \multicolumn{3}{|c|}{ Jumlah } & 10 & $100 \%$ \\
\hline
\end{tabular}

Berdasarkan Tabel 7, dapat disimpulkan bahwa atlet yang memiliki kondisi VO2Max dengan kategori baik sekali berjumlah $0(0 \%)$, baik $0(0 \%)$, cukup 5 atlet (62.5\%), kurang 3 atlet (37.5\%), sedangkan kategori sangat kurang 0 $(0 \%)$. Secara keseluruhan hasil penelitian yang diperoleh dari klub futsal putri Bengkulu Raya Angels yang berjumlah 7 atlet menunjukan tingkat kondisi fisik VO2Max atlet yaitu nilai minimum VO2Max sebesar $=24.4$, nilai maksimal VO2Max sebesar $=32.4$, dan nilai rata-rata sebesar $=28.26$.

Tabel 8. Persentase Tingkat Kondisi Fisik $\mathrm{VO}_{2} \mathrm{Max}$ Klub Futsal Bunga Kenanga Kota Bengkulu

\begin{tabular}{ccccc}
\hline NO & $\boldsymbol{V O}_{2} \boldsymbol{M A} \boldsymbol{X}$ & Kategori & Frekuensi & Persentase \\
\hline $\mathbf{1 .}$ & $\geq 49$ & Baik Sekali & 0 & $0 \%$ \\
$\mathbf{2 .}$ & $39-48,9$ & Baik & 0 & $0 \%$ \\
$\mathbf{3 .}$ & $31-38,9$ & Cukup & 2 & $28,57 \%$ \\
$\mathbf{4 .}$ & $24-30,9$ & Kurang & 5 & $71,43 \%$ \\
$\mathbf{5 .}$ & $<23,9$ & Sangat Kurang & 0 & $0 \%$ \\
& & & $\mathbf{1 0}$ & $\mathbf{1 0 0 \%}$ \\
\hline
\end{tabular}

Berdasarkan Tabel 8, dapat disimpulkan bahwa atlet yang memiliki kondisi VO2Max dengan kategori baik sekali berjumlah $0(0 \%)$, baik $0(0 \%)$, cukup 2 atlet (28.57\%), kurang 5 atlet (71.43\%), sedangkan kategori sangat kurang $0(0 \%)$. Secara keseluruhan hasil penelitian yang diperoleh dari klub futsal putri Bengkulu Raya Angels yang berjumlah 8 atlet menunjukan tingkat kondisi fisik VO2Max atlet yaitu nilai minimum VO2Max sebesar $=27.6$, nilai maksimal VO2Max sebesar $=33.2$, dan nilai rata-rata sebesar $=30.05$. 
Tabel 9. Persentase Tingkat Kondisi Fisik $\mathrm{VO}_{2} \mathrm{Max}$ Klub Futsal UKM FORKIP UNIB Kota Bengkulu

\begin{tabular}{rcccc}
\hline NO & $\boldsymbol{V O}_{\mathbf{2}} \boldsymbol{M} \boldsymbol{A} \boldsymbol{X}$ & Kategori & Frekuensi & Persentase \\
\hline $\mathbf{1 .}$ & $\geq 49$ & Baik Sekali & 0 & $0 \%$ \\
$\mathbf{2 .}$ & $39-48,9$ & Baik & 0 & $0 \%$ \\
3. & $31-38,9$ & Cukup & 4 & $50 \%$ \\
$\mathbf{4 .}$ & $24-30,9$ & Kurang & 4 & $50 \%$ \\
$\mathbf{5 .}$ & $<23,9$ & Sangat Kurang & 0 & $0 \%$ \\
& & & $\mathbf{1 0}$ & $\mathbf{1 0 0 \%}$
\end{tabular}

Berdasarkan Tabel 9 dapat disimpulkan bahwa atlet yang memiliki kondisi VO2Max dengan kategori baik sekali berjumlah $0(0 \%)$, baik $0(0 \%)$, cukup 4 atlet (50\%), kurang 4 atlet (50\%), sedangkan kategori sangat kurang $0(0 \%)$.

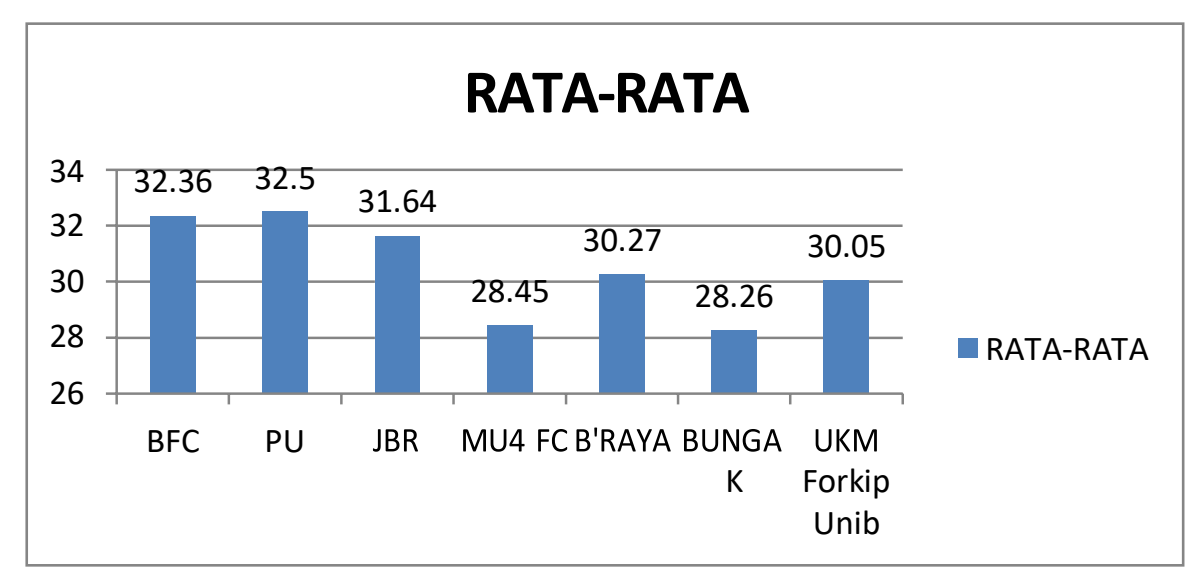

Gambar 1. Diagram Batang Distribusi Rata-rata Vo2Max Klub Futsal Putri se-Kota Bengkulu

Berdasarkan gambar 1 dapat disimpulkan bahwa hasil rata-rata VO2Max diperoleh klub Bengkulu Futsal Club dikategorikan "cukup" dengan hasil rata-rata 32.36, klub Patrimony United dikategorikan “cukup” dengan hasil rata-rata 32.05, klub Jugador Bonita Raflesia dikategorikan “cukup” dengan hasil rata-rata 31.64, klub MU4 FC dikategorikan "kurang" dengan rata-rata 28.45, klub Bengkulu Raya Angels dikategorikan "kurang" dengan rata-rata 30.27, klub Bunga Kenanga dikategorikan "kurang” dengan rata-rata 28.26, klub Futsal UKM FORKIP UNIB dikategorikan "kurang" dengan rata-rata 30.05. Dari hasil rata-rata keseluruhan atas 7 klub futsal putri di kota Bengkulu bahwa rata-rata kondisi fisik VO2Max atlet futsal putri di kota Bengkulu yaitu 30.61 jika dimasukan kedalam norma berada pada kategori kurang. 


\section{PEMBAHASAN}

Penelitian ini bertujuan untuk mengetahui tingkat kondisi fisik VO2Max klub futsal putri di kota Bengkulu. Dari hasil rata-rata VO2Max diperoleh klub Bengkulu Futsal Club dikategorikan "cukup" dengan hasil rata-rata 32.36, klub Patrimony United dikategorikan "cukup" dengan hasil rata-rata 32.05, klub Jugador Bonita Raflesia dikategorikan "cukup" dengan hasil rata-rata 31.64, Berdasarkan normal yang telah ditentukan maka klub MU4 FC dikategorikan "kurang" dengan rata-rata 28.45, klub Bengkulu Raya Angels dikategorikan "kurang" dengan rata-rata 30.27, klub Bunga Kenanga dikategorikan "kurang" dengan rata-rata 28.26, klub Futsal UKM FORKIP UNIB dikategorikan "kurang" dengan rata-rata 30.05 .

Dari hasil rata-rata keseluruhan 7 klub futsal putri di kota Bengkulu bahwa rata-rata kondisi fisik VO2Max atlet futsal putri di kota Bengkulu yaitu 30.61 jika dimasukan kedalam norma berada pada kategori kurang. Merujuk dari hasil penelitian dan kesimpulan dapat dijelaskan bahwa tingkat kondisi fisik VO2Max klub futsal putri di kota Bengkulu dikategorikan kurang,

Hasil penelitian terdahulu menunjukan bahwa kondisi fisik VO2Max yang dimiliki oleh atlet futsal putri di kota Bengkulu berada pada kategori cukup yang saat itu masih terdiri dari 3 klub futsal putri di kota Bengkulu yang aktif dalam latihan maupun mengikuti pertandingan. Sehingga hasil penelitian menunjukan hasil yang hampir sama yaitu kondisi fisik VO2Max atlet futsal putri kota Bengkulu sangat perlu untuk ditingkatkan karena masih berada pada kategori kurang dan cukup dengan hal ini atlet dan pelatih harus lebih bekerja sama lagi untuk meningkatkan kondisi fisik VO2Max agar menjadi lebih baik lagi, jika frekuensi latihan kurang, maka tingkat kebugaran jasmani pun kurang. Latihan yang tidak terprogram juga memberikan peluang bagi atlet untuk membuat latihan kurang terkendali (Arifianto \& Raibowo, 2020). Ada tiga kemungkinan yang bisa terjadi yaitu: terlalu berat sehingga melebihi kemampuan atlet, terlalu ringan, dan tidak sesuai dengan kemampuan sehingga adaptasi latihan fisik kurang optimal. Proses latihan dimulai dari yang mudah ke yang sukar pada proses ini dimulainya tahap kognitif dalam belajar (Alexon et al., 2021). Upaya seorang pelatih dalam meningkatkan kondisi fisik atlet dapat dilakukan dengan cara memberikan 
program latihan yang tepat kepada atlet (Ilham et al., 2021; Nopiyanto \& Raibowo, 2020), khususnya dalam kondisi fisik VO2Max atletnya (Bafirman \& Wahyuri, 2019; Purnomo et al., 2019), karena karakteristik pemain futsal memerlukan kondisi fisik yang prima. Kondisi fisik sangat berperan dalam menciptakan pola permainan yang efektif (Hatfield \& Hilman, 2001). Untuk menjadikan pemain futsal yang mempunyai prestasi, diperlukan pembinaan yang tepat dalam proses latihan, karena prestasi yang terbaik adalah salah satu tujuan dari setiap atlet maupun pelatih dalam olahraga prestasi dan hal ini bisa diraih jika atlet memiliki kondisi fisik VO2Max baik dan diikuti dengan teknik, taktik serta strategi dalam bermain.

Prestasi dalam olahraga sangat dipengaruhi oleh faktor-faktor yang sangat berhubungan dengan kemampuan-kemampuan dalam diri atlet, yang meliputi: kemampuan fisik, kemampuan teknik, taktik dan psikologis (Triananda et al., 2021). Untuk meningkatkan keterampilan dan prestasinya semaksimal mungkin ada empat aspek yang perlu diperhatikan dan dilatih secara seksama yaitu latihan fisik, teknik, taktik dan mental. Kondis fisik merupakan hal utama yang harus dimiliki oleh atlet futsal, selain dari unsur kondisi fisik yang lain, seperti halnya kecepatan dan kelincahan (Raibowo, Ilahi, et al., 2021). VO2Max memegang peranan penting bagi cabang olahraga futsal, namun yang lebih penting lagi adalah bukan hanya besaran VO2Max, tetapi besaran persentase penggunaan VO2Max pada saat pertandingan maupun latihan (Nala, 2015)

Berdasarkan hal tersebut, maka untuk meningkatkan prestasi futsal putri di kota Bengkulu perlu ditambahkan beberapa upaya seperti menambah jam latihan agar lebih efisien, sebaiknya frekuensi latihan ditambah minimal 3 kali dalam seminggu, pelatih klub futsal putri sebaiknya membuat program latihan yang lebih tertata dan menarik namun tetap merujuk pada tujuan yang ingin dicapai dalam latihan, seperti membagi porsi latihan antara teknik, taktik, dan latihan untuk meningkatkan kondisi VO2Max atletnya, kondisi fisik adalah syarat yang harus dimiliki oleh seorang atlet untuk meningkatkan prestasi. Bahkan hal ini sebagai landasan tolak ukur sebagai awalan untuk olahraga prestasi (Pratama, 2015) dan seharusnya atlet klub futsal putri di kota Bengkulu lebih serius dalam mengikuti latihan dan menambah jam latihan sendiri, selain itu dari klub sendiri harus siap 
memfasilitasi agar pelatih dan atlet bisa menjalankan program latihan, dan sebaiknya klub juga memfasilitasi minimal 1 bulan sekali melakukan pertandingan persahabatan karena hal ini merupakan bagian terpenting juga, karena pelatih bisa melihat perkembangan atlet-atletnya dan membentuk mental atlet sendiri. Selain untuk meningkatkan prestasi, daya tahan VO2Max juga penting untuk atlet futsal putri, karena VO2Max salah satu kunci penting dalam setiap klub untuk meningkatkan prestasinya

Penelitan ini berada pada kategori kurang, dengan ini ada beberapa masalah yang terjadi di klub futsal putri di kota Bengkulu khususnya 1 tahun terakhir ini, karena tidak bisa dipungkiri saat pandemi covid 19 masuk ke Negara Indonesia membuat semua aktivitas kegiatan olahraga termasuk olahraga futsal pun dilarang untuk melakukan latihan hal ini sangat mempengaruhi klub futsal putri di kota Bengkulu dalam menjalankan latihan. Dampak pandemi covid 19 terhadap dunia olahraga yakni berbagai ajang event olahraga banyak yang tertundah diantaranya otomotif, sepak bola, golf, futsal, sepeda, olimpiade dan atletik serta latihan pun diistirahatkan sementara waktu (Susanto, 2020), hal ini juga berdampak di beberapa klub yang baru dibentuk di kota Bengkulu yang baru berumur satu tahun dan bertepatan dengan pandami di indonesia, sehingga program latihan yang diberikan pelatih pun tidak bisa berjalan dengan baik, dan jam latihan pun semakin sedikit dan tidak teratur. Motivasi dari atlet sendirinya sangat kurang dimana atlet futsal putri di kota Bengkulu sangat kurang kesadarannya untuk menambah latihan sendiri diluar jam latihan yang telah dijadwalkan, sehingga hal ini membuat kondisi fisik VO2Max atlet klub futsal putri di kota Bengkulu masih berada pada kategori kurang. Motivasi pada diri atlet merupakan bagian terpenting yang harus dimiliki atlet agar bisa memotivasi diri untuk selalu menjalankan latihan dan menambah latihan dengan sendiri tanpa melibatkan pelatih (Nopiyanto et al., 2021)

\section{KESIMPULAN}

Berdasarkan hasil perolehan data Survei Kondisi Fisik VO2Max Atlet Pada Klub Futsal Putri di Kota Bengkulu. Dari 7 klub futsal putri yang ada di kota Bengkulu yang diteliti, maka dapat diketahui keseluruhan hasil dari kondisi fisik VO2Max atlet futsal putri yang ada di kota Bengkulu, dari data yang telah 
dijelaskan peneliti bahwa atlet futsal putri di kota Bengkulu memiliki daya tahan VO2Max dengan nilai rata-rata keseluruhan 30.61 jika dimasukan dalam norma yaitu berada dikategorikan kurang.

\section{REFERENSI}

Alexon, Defliyanto, Pujianto, D., Sutisyana, A., \& Burlian, A. (2021). The Effect of Multiball Training on The Precision of Forehand Button in Table Tennis Extracurricular Student's of SMA Negeri 7 Bengkulu City. Kinestetik: Jurnal Ilmiah Pendidikan Jasmani, 5(17). https://doi.org/10.33369/jk.v5i2.17817

Arifianto, I., \& Raibowo, S. (2020). Model Latihan Koordinasi dalam Bentuk Video Menggunakan Variasi Tekanan Bola Untuk Atlet Tenis Lapangan Tingkat Yunior. STAND: Journal Sport Teaching and Development, 1, 4955. https://doi.org//10.36456/j-stand.v1i2.2671

Arifianto, I., Raibowo, S., \& Jatra, R. (2021). Groundstroke Training Games Dalam Bentuk Video untuk Atlet Junior Tenis Lapangan. Jurnal Menssana, 6(1), 12-22. https://doi.org/10.24036/MensSana.06012021.18

Arikunto, S. (2010). Metode Penelitian. Bina Aksara.

Bafirman, \& Wahyuri, A. S. (2019). Pembentukan Kondisi Fisik. In Rajawali Pers (1st ed.). Raja Grafindo Persada.

Hatfield, B. ., \& Hilman, C. (2001). The Psychophyhsiology of Sport: A Mechanistic Understanding of The Psychology of Superior Performance (2nd ed.). Handbook of Sport Psychology.

Ilham, T. R., Pujianto, D., \& Arwin. (2021). Pengaruh Latihan Plyometrics ( Hurdle Hops dan Ladder Drill ) Terhadap Kecepatan Dribbling Futsal Putri Tim Jugador Bonita Rafflesia. Sport Gymnastics: Jurnal Ilmiah Pendidikan Jasmani, 2(1), 34-45. https://doi.org/10.33369/gymnastics

Lhaksana, J. (2011). Taktik \& Strategi FUTSAL Modern. Jakarta: Be Champion.

Nala, I. G. (2015). Prinsip Pelatihan Fisik Olahraga. Udayana University Press.

Nopiyanto, Y. E., \& Raibowo, S. (2020). Pelatihan Olahraga Futsal sebagai Sarana Mengurangi Aktivitas Game Online pada Anak-Anak di Kelurahan Mangunharjo. JURPIKAT (Jurnal Pengabdian Kepada Masyarakat) Politeknik Kebumen, 1(2), 114-124. https://doi.org//10.37339/jurpikat.v1i2.264

Nopiyanto, Y. E., Raibowo, S., \& Prabowo, G. U. (2021). Psychological Characteristics of Athletes at Pusat Pendidikan dan Latihan Pelajar ( PPLP ) in Bengkulu. Journal Sport Area, 6(1), 37-43. https://doi.org/doi.org/10.25299/sportarea.2021.vol6(1).5572

Purnomo, E., Gustian, U., \& Puspita, I. D. (2019). Pengaruh Program Latihan terhadap Peningkatan Kondisi Fisik Atlet Bolatangan Porprov Kubu Raya. JSES: Journal of Sport and Exercise Science, 2(1), 29. https://doi.org/10.26740/jses.v2n1.p29-33

Raibowo, S., Ilahi, B. R., Prabowo, A., Nopiyanto, Y. E., \& Defliyanto. (2021). Penguasaan Keterampilan Dasar Futsal UKM FORKIP Universitas Bengkulu. Jurnal Pendidikan Kesehatan Rekreasi, 7(2), 333-341. https://doi.org/10.5281/zenodo.4897656 
Raibowo, S., Jatra, R., Prabowo, A., Nopiyanto, Y. E., \& Ilahi, B. R. (2021). Anxiety and Concentration of Tennis Chair Umpire. Halaman Olahraga Nusantara (Jurnal Ilmu Keolahragaan), 4(Ii), 271-281. https://doi.org/10.31851/hon.v4i25640

Sugiyono. (2018). Metode Penelitian Kuantitatif, Kualitatif dan R\&D. Bandung: Alfabeta.

Triananda, A., Syafrial, \& Nopiyanto, Y. E. (2021). Karakteristik Psikologis Atlet PON Bengkulu Ditinjau dari Cabang Olahraga Individu. Sport Gymnastics: Jurnal Ilmiah Pendidikan Jasmani, 2(1), 126-137. https://doi.org/10.33369/gymnastics 